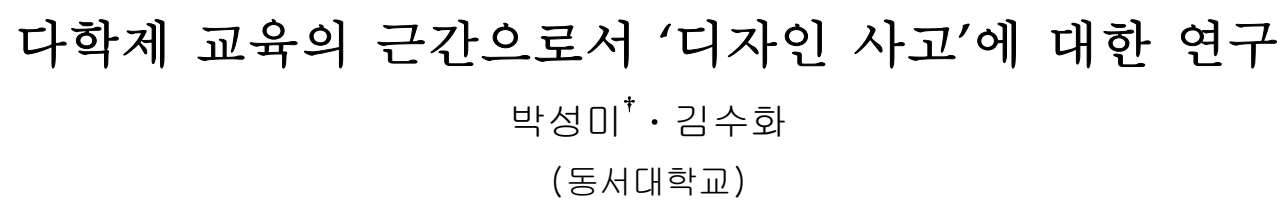

\title{
The Study of Design Thinking as Foundation of Multidisciplinary Education
}

\author{
Sung-Mi PARK ${ }^{\dagger} \cdot$ Sue-Hwa KIM \\ (Dongseo University)
}

\begin{abstract}
This study aims to reflect experts' opinions in analyzing a design thinking as foundation of multidisciplinary education. For this purpose, a delphi survey was conducted with 20 experts in three sessions from May 1 to June 25, 2012. To analyze the collected data, descriptive statistics, including frequency, percentage, the mean, and standard deviation were implemented, and internal reliability test on the survey instrument was carried out for statistical processing. The main results are as follows : First, the delphi analysis on intuitive thinking of design thinking suggested 7 items (to pursue the possibility of outside, to pursue the possibility of applying new forms of technology, content planning, facing a complex real-world phenomena etc.). Second, the delphi analysis on logical thinking of design thinking suggested 7 items (executed repeatedly, reasoning and verification, artificial intelligence, a decision support system etc.) Third, the delphi analysis on subjective thinking of design thinking suggested 9 items (user experience measuring, user satisfaction ratings, user requirements analysis, user interface design, behavioral responses of the human etc.). Fourth, the delphi analysis on objective information of design thinking suggested 8 items (information management system, simulation, production process, information exchange and sharing etc.). According to the results of the delphi analysis, design thinking can be seen as the foundation of multidisciplinary education. Suggestions were made for discussion about the main results and further researches.
\end{abstract}

Key words : Multidisciplinary education, Design thinking, Intuitive thinking, Logical thinking, Subjective thinking, Objective information

$$
\text { I. 서 론 }
$$

최근에는 미학과 경제학, 인문학과 자연과학, 심리학과 정치학 등 거의 모든 학문들이 단순히 상호 교류하는 것을 넘어 서로 적극적으로 학문
간 융합하려는 추세를 보이면서 다학제 교육에 대한 논의가 활발하게 이루어지고 있다(강성종, 김용욱, 2010; 김유신, 윤상근, 안호영, 2012; 오헌 석, 김희정, 배형준, 서동인, 김한솔, 2012).

특히 디자인 교과교육에서는 미학이라는 단일

† Corresponding author : 051-320-1866, psm1994@dongseo.ac.kr

* 이 논문은 2011년도 동서대학교 "Dongseo Frontier Project" 지원에 의하여 이루어진 것임. 
학문분야의 본질을 넘어 다양한 응용학문과 사회 현상을 통합하여 새로운 발상과 혁신을 도모하려 한다(Bhavnani \& Aldridge, 2000). 이는 현대사회 의 급변하는 사회현상을 고려해볼 때, 인간의 다 양한 요구를 분절된 단위 학문으로 설명하는데 한계가 있기 때문이다(강성종, 김용욱, 2010; 민경 우, 이순종, 채승진, 2005). 이러한 이유로 디자인 교과교육에서 다학제 접근은 매우 이상적인 교육 패러다임으로 수용되고 있다(박정순, 2004; 이순 종, 김종원, 주우진, 채승진, 윤수현, 2007). 이로 인해 디자인 교과교육에서 학제간 통합, 융합을 추구하려는 학문분야로는 공학, 과학, 인간학, 사 회과학 등을 들 수 있다.

한편, 현실적으로 다학제 간의 순수한 연계는 사실상 어렵다는 관점도 대두되고 있다(강현석, 방기용, 2012; 노상우, 안동순, 2012; Bhavanai \& Aldridge, 2000). 그 이유는 한 분야가 다른 한 분야에 포섭되거나 일방적으로 이용당할 수 있으 며, 또한 다학제 분야가 융합되는 협력과정에서 각 분야의 전문성을 상실할지도 모른다는 우려 때문이다(이순종 외, 2007).

그러나 다학제 교육의 가치는 서로 다른 학제 의 지식이 함께 어우러져 한층 더 발전된 문제해 결을 도출할 수 있다는데 있다(이의수, 조성구, 이용한, 이명천, 염세경, 2006). 이상의 연구들을 종합해보면, 다학제간 연계교육의 형태는 그 순 기능과 역기능이 존재하지만 분명코 교육적 함의 가 있다는 것을 알 수 있다.

그러나 실제로 디자인 교과에서 다학제 교육은 어떻게 구현 가능한 것인지에 대하여 충분한 설 명이 이루어지지 않고 있다(조성구, 이의수, 이명 천, 이용한, 염세경, 2008; Leong \& Clark, 2003; Teal, 2010).

물론, 예술과 과학(강정하, 최인수, 2006), 철학 과 공학(정영기, 2012)간 학제융합 연구들을 살펴 보면, 단일학문의 고유한 특징상 상호 연결될만 한 접점을 찾기 힘든 학문분야 간에도 두 학제간 연결, 통합의 가능성을 시사하고 있다. 더 나아가
다학제의 실천 가능한 기반으로서 인간·가치·창의 성 등을 주요 키워드로 제안하고 있다.

다시 말하면, 다학제 교육은 대부분의 인간이 혜택을 누릴 수 있는 가치로운 것을 추구하려는 목적의식에서 창의적인 문제 해결을 시도한다는 관점에 의거하여 다학제의 실천 가능성을 강조하 고 있는 것이다(노상우, 안동순, 2012; 정영기, 2012).

그러나 여기서 다학제가 어우러지기만 하면, 자연스럽게 인간에게 가치롭고 새로운 창의적 문 제해결에 도달하는 것은 아니다. 이는 각 분야의 학제가 개연성있게 연결, 통합될 수 있는 '교역지 대(trading zone)'라는 매개의 공간이 제공되어야 가능하다(오헌석 외 2012; 정연숙, 김현경, 2011). 매개의 공간으로서 '교역지대'는 기업혁신 혹은 사회혁신을 이루는 보편적 방법론으로 수용되는 디자인 사고로 대변할 수 있다(박정순, 2004; 이 순종 외, 2007; 이지선, 윤주현, 2009; Cross, 1990; Jay, 1984; Leong \& Clark, 2003; Teal, 2010).

디자인 사고는 현존하는 상황에서 더 나은 상 황으로 바꾸려는 개인의 새로운 문제해결 방식이 다(민경우 외, 2005; 정연숙, 김현경, 2011). 일반 적으로 학문분야별 문제해결 방식은 다양한데, 과학에서의 논리적 사고, 예술에서의 직관적 사 고, 공학에서의 객관적 정보활용, 인문학에서의 주관적 사고 등이 있다(강정하, 최인수, 2008; 이 대현, 2008; 윤호창, 2004).

디자인 사고는 각 학문 분야에서 설명하는 문 제해결 방식에만 머물지 않고 새로운 개념 도출 과 구상 그리고 실현을 위하여 직관적 사고와 논 리적 사고, 직관과 주관적 사고 등의 조화를 이 루려는 것이다(Jay, 1984). 이는 곧 예술, 과학, 공 학, 인문학 등과의 원만한 연결과 통합을 의미한 다.

이처럼 디자인 사고는 그 자체의 특징상 융합 의 의미를 담고 있으므로 다학제 교육의 이론적 근간, 즉 교역지대로서 충분한 설명력이 있다고 
볼 수 있다(박정순, 2004; 이지선, 윤주현, 2009). 그럼에도 불구하고 디자인 사고는 그동안 미학분 야에서 단편적으로 적용되었다(이의수 외, 2006; 이지선, 윤주현, 2009). 물론 공학, 과학 분야에서 디자인 사고를 적용하는 연구를 찾아볼 수 있으 나 다학제 형태에서 디자인 사고의 적절성을 설 명하는 연구는 찾아보기 힘들다.

그러므로 미학 분야에서 제한된 설명을 하고 있는 디자인 사고를 다학제 형태로서 응용 및 수 용 가능한지를 경험적으로 검토해 볼 필요가 있 다고 생각한다.

이에 본 연구의 목적은 디자인 교과에서 다학 제 교육체제로의 용이한 전환과 실질적인 결과를 도출할만한 교역지대로서 디자인 사고를 탐색하 는 시론적 연구를 하고자 한다.

\section{II. 이론적 배경}

\section{1. 다학제 교육의 근간, 디자인 사고}

다학제란 상이한 학문분야에서 다른 분야의 관 심사를 자신의 것으로 전환하는 것이 아니라 논 리적 협상을 통하여 대안을 마련하는 것이다. 여 기서 논리적 협상은 여러 분야, 영역, 문화, 관행 등에서 걸쳐있는 매개의 공간, 즉 '교역지대'를 도출하는 것으로 볼 수 있다(오헌석 외, 2012; 정 연숙, 김현경, 2011).

'교역지대'란 서로 다른 전문성을 지닌 학자나 연구팀이 만나서 서로의 언어를 혼합하고 소통함 으로써 공통의 언어를 만들어내는 공통분모이다 (오헌석 외, 2012; Cross, 1990; Leong \& Clark, 2003). 여기서 '교역지대'는 바로 다학제 교육의 실천 가능한 방안이 될 수 있음을 알 수 있다. 그런데 매개의 공간, 즉 '교역지대'를 도출하기 위해서는 보다 근원적인 각 학문분야의 고유한 특성을 고려하여 연결 및 논리적 통합을 잘 구현 할만한 이론적 근거가 필요하다.

이에 본 연구에서는 '교역지대'를 적절하게 설
명할 수 있는 이론적 근거로서 디자인 사고를 고 려하고자 한다(이지선, 윤주현, 2009).

디자인 사고는 Herbert Simon에 의해 알려진 것으로 특수한 디자인 영역에서 설명되는 협의의 개념이 아니다. 이는 매우 보편적인 영역에서 설 명되는 광의의 개념이다. 이를 테면, '모든 사람 은 디자이너이다'라는 대전제 하에 현존하는 상 황에서 더 나은 상황으로 바꾸려는 개인의 문제 해결 방식을 디자인 사고라고 일컫는다(민경우 외, 2005; 이정열, 이주명, 2010; 정연숙, 김현경, 2011; Jay, 1984; Thomson, 1998).

여기서 개인의 문제해결 방식은 학문분야별로 다양하다. 일반적으로 학문분야별 주된 흐름으로 등장하는 문제해결 방식에는 과학의 논리적 사 고, 예술의 직관적 사고, 공학의 객관적 정보활 용, 인간학의 주관적 사고 등을 열거할 수 있다 (강정하, 최인수, 2008; 민경우 외, 2005; 이대현, 2008; 윤호창, 2004; 정연숙, 김현경, 2011; 최영 수, 강현석, 2011).

디자인 사고를 여러 학문 분야에 통합하려는 연구들(이지선, 윤주현, 2009; 조성구 외, 2008; Leong \& Clark, 2003; Teal, 2010)을 살펴보면, 디자인 사고는 사회, 문화, 경제, 정치, 환경 등 인간생활의 모든 제반 문제를 가치롭게 추구하며 새로운 지식창출과 더불어 더 나은 방향으로 문 제해결을 시도할 수 있다는 근간을 제공하고 있 다. 이는 디자인 사고가 여러 학문분야에서 논리 적 사고와 직관적 사고로 혹은 직관적 사고와 주 관적 사고로, 때로는 주관적 사고와 객관적 정보 활용 등으로 결합하거나 통합하여 의미있는 설명 을 해주고 있기 때문이다(Jay, 1984).

이처럼 디자인 사고는 단일학문 분야에서 설명 하는 문제해결 방식을 뛰어넘어 새로운 개념의 도출과 구상 그리고 실현을 위하여 학문분야별 주된 문제해결 방식들, 즉 논리적 사고와 직관적 사고, 직관적 사고와 주관적 사고 등의 조화를 이룰 수 있는 근거가 된다고 본다. 이는 곧 공학, 과학, 예술, 인문학 등의 원만한 연결과 통합을 
다학제 교육의 근간으로서 ‘디자인 사고'에 대한 연구

〈표 1〉 다학제 교육의 이론적 근간으로서 디자인 사고를 시사하는 일련의 연구들

\begin{tabular}{|c|c|c|c|}
\hline \multirow{2}{*}{ 연구자 } & \multicolumn{2}{|r|}{ 다학제 교육의 가능성 제시 } & \multirow{2}{*}{ 디자인 사고의 역할 } \\
\hline & 강조점 & 세부내용 & \\
\hline $\begin{array}{l}\text { 최영수, } \\
\text { 강현석 } \\
\text { (2011) }\end{array}$ & $\begin{array}{l}\text {-문제해결과정에서 } \\
\text { 직관과 분석의 } \\
\text { 역할을 강조 }\end{array}$ & $\begin{array}{l}\text {-Bruner에 의하면, 문제해결과정에서 직관적 } \\
\text { 사고와 분석적 사고의 상호보완성을 밝힘 }\end{array}$ & $\begin{array}{l}\text {-수학, 과학 분야와 예술, } \\
\text { 인문학의 융합을 강조 }\end{array}$ \\
\hline $\begin{array}{l}\text { 이대현 } \\
\text { (2008) }\end{array}$ & $\begin{array}{l}\text {-수학에서 직관의 } \\
\text { 역할을 강조 }\end{array}$ & $\begin{array}{l}\text {-직관적 사고와 논리적 사고의 상호보완성 } \\
\text {-직관은 자연과학, 예술분야, 인문과학 } \\
\text { 분야에서 중요한 역할을 함 }\end{array}$ & $\begin{array}{l}\text {-과학과 예술, 인문과학의 } \\
\text { 융합을 강조 }\end{array}$ \\
\hline $\begin{array}{l}\text { 강정하, } \\
\text { 최인수 } \\
\text { (2008) }\end{array}$ & $\begin{array}{l}\text {-창의성에서 과학과 } \\
\text { 예술의 역할 강조 }\end{array}$ & $\begin{array}{l}\text {-창의적 활동 영역에 있어 완성도를 높이기 } \\
\text { 위한 차원에서 과학과 예술의 통합 접근성 } \\
\text { 높음. 즉 논리와 직관의 통합 }\end{array}$ & -과학과 예술의 융합 \\
\hline
\end{tabular}

의미하는 것이다(이정열, 이주명, 2010).

이러한 관점에 따라, 디자인 사고는 다학제 교 육의 이론적 근간, 즉 교역지대로서 적절한 설명 을 제공해줄 수 있다고 본다.

그러나 지금까지 디자인 사고는 주로 미학 분 야에서 단편적으로 설명되었을 뿐이다(이의수 외, 2006; 이지선, 윤주현, 2009; Jay, 1984). 그러므로 본 연구는 상이한 학문분야간 논리적 협상을 위 한 매개의 공간, 즉 '교역지대'로서 디자인 사고 를 관련 학문분야의 관점에서 다학제 교육의 가 능성을 탐색하고자 한다. 이에 단일 학문분야에 서 단편적으로 설명되었던 디자인 사고의 변인들 을 직관적 사고, 논리적 사고, 주관적 사고, 객관 적 정보 활용 등으로 구분하여 그 구체적인 내용 과 변인들간의 상호 관련성을 규명해보고자 한 다.

\section{2. 디자인 사고의 구인}

다학제 교육의 이론적 근간으로서 디자인 사고 의 역할을 시사하는 일련의 연구를 정리하면 <표 $1>$ 과 같다.

\section{가. 직관적 사고}

직관에 대한 논의의 역사를 살펴보면, 직관적 사고는 전통적으로 예술, 인문학 분야에서 창의 적 매개체로 활용되어왔다. 즉 직관은 특수한 참 된 지식의 원천으로 인식하거나 궁극적인 진리에 이르는 기제로서 다루어왔다(이정열, 이주명,
2010; 정연숙, 김현경, 2011). 이러한 직관은 '창의 적' 혹은 '창조'의 도구로 수용되지만, 문제해결 과정에서 때로 부정적인 영향을 주기도 한다. 이 는 직관이란 매우 주관적이고, 개인적 편견에 사 로잡힐 수 있으므로 이를 보완하기 위하여 논리 적 사고가 필요하다는 것을 알 수 있다. 이러한 관점에 의하여, 직관적 사고와 논리의 통합은 곧 창의적 문제해결을 도출할 수 있을 것으로 생각 된다(최영수, 강현석, 2011). 따라서 직관적 사고 는 다학제 교육를 통해 새로운 진리를 찾는 학문 분야에서 반드시 고려되어야 할 중요한 변인임을 알 수 있다.

나. 논리적 사고

논리적 사고는 전통적으로 수학과 과학의 문제 해결 과정에서 활용되었다(강정하, 최인수, 2008; 윤호창, 2004; Custer \& Claborne, 1992). 여기서 논리적 사고란 주어진 정보를 이용하여 인과관계 라는 전제로부터 결론을 이끌어 내는 사고를 말 한다. 그런데 논리적 사고를 요구하는 수학적 문 제해결 과정에 직관의 중요성을 설명하는 연구 (이대현, 2008)를 찾아보면, 수학의 역사에 직관 의 긍정적인 기여를 엿볼 수 있다. 직관의 속성 을 한가지로 규정하기가 쉽지 않을지라도 오랜 역사를 통해 합리적이고 자기모순이 없는 수학 체계를 만들려고 노력해 온 수학의 역사를 살펴 볼 때, 수학에서 직관은 참된 지식을 발견하는 근원으로 간주하고 있다. 이는 직관과 논리가 통 
합되어 다학제 교육의 목적에 쉽게 도달하게 하 는 디자인 사고의 개념으로써 수용될 수 있음을 의미한다.

다. 주관적 사고

주관적 사고는 대개 인간학에서 인간에 대한 이해를 대전제로 존재적 가치를 설명하고 있다. 여기서 주관이란 '여러 현상을 의식하며 사물을 생각하는 마음의 움직임과 자기만의 생각과 또는 자기만의 치우친 생각'이라고 할 수 있다(곽은혜, 이은경, 2011; 윤호창, 2004).

그러므로 주관적 사고에서 강조하는 것은 '어 떻게(how)' 말하는가 하는 것이다. 그러므로 인 간학에서는 '어떻게'를 중요시한다. 즉 주관적 사 고의 관심은 존재의 내면성(inwardness), 인간 그 자체에 초점이 맞추어져 있다. 따라서 주관적 사 고는 다학제를 통해 새로운 진리를 찾는 주체로 서 반드시 고려해야 할 중요한 변인임을 알 수 있다.

\section{라. 객관적 정보의 활용}

앞에서 설명한 주관과 대치되는 객관이란 '인 식의 주체에 대한 내용이나 대상, 정신력, 육체적 자아에 대한 공간적 외계, 자기 혼자만의 생각에 서 벗어나 제 3 자의 입장에서 사물을 보거나 생각 하는 일이다(곽은혜, 이은경, 2011; 윤호창, 2004). 그러므로 객관적인 입장의 관심은 오로지 '사고 의 내용'에 초점이 맞추어져 있다.

객관적인 입장에서는 사고의 내용이 무엇인지, 즉 그 지식이 무엇에 관하여 말하고 있는가가 중 요시된다. 이는 다학제 교육의 근간에 있어 '내용 그 자체'에 대한 설명을 해주는 것이므로 역시 고려되어야 할 또 다른 중요한 변인임을 알 수 있다.

마. 디자인 사고 변인들의 상호보완적 관계

이상에서 살펴본 디자인 사고의 변인들을 종합 하여 개념도를 설정하면 [그림 1]과 같다.

[그림 1]에 의하면, 직관적 사고는 지식 창출을 위한 촉매적인 역할을 한다고 볼 수 있다. 그러
나 직관에 의한 오류가 발생할 수 있으므로 이를 뒷받침하는 논리적 사고가 포함되어야 한다(이대 현, 2008; 이정열, 이주명, 2010). 덧붙여 논리적 사고는 모든 학문분야가 과학이라는 전제 하에 체계적 사고과정을 통해 지식을 발견하는 알고리 즘 그 자체이므로 논리적 사고는 다학제의 기초 적인 기반이 될 수 있다(최영수, 강현석, 2011).

더 나아가 '무엇(what)'을 말하는가 하는 객관 적 정보의 활용과 '어떻게(how)'말하는가 하는 주관적 사고는 다학제의 대상을 주체와 객체로 설명하는 양극의 변인임과 아울러 공유 변인으로 볼 수 있다(윤호창, 2004).

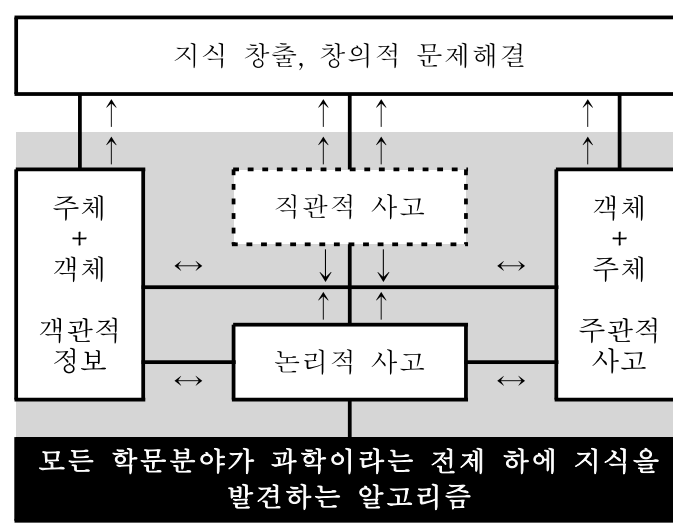

[그림 1] 디자인 사고 변인들의 상호보완 관계

이상의 직관적 사고, 논리적 사고, 주관적 사고 와 객관적 정보 활용은 통합, 융합되어 다학제 교육의 근간으로서 새로운 지식을 창출하고 창의 적 문제해결에 쉽게 도달할 수 있으리라 짐작한 다. 따라서 본 연구는 다학제 교육의 근간으로서 직관적 사고, 논리적 사고, 주관적 사고, 객관적 정보활용 등을 포함하는 디자인 사고를 면밀히 탐색하기 위하여 각 학문분야의 전문가를 대상으 로 델파이 조사분석을 하였다.

\section{III. 연구 방법}

\section{1. 연구절차 및 대상}


본 연구는 다학제 교육의 근간으로서 디자인 사고에 대한 전문가들의 의견을 수렴하기 위하여 델파이 연구를 수행하였다.

이를 위하여 델파이 패널의 수는 최초 20 명의 델파이 패널을 섭외하고 연구를 진행하였으나, 연구를 진행하는 과정에서 4 명의 패널의 응답률 이 저조하여 제외하고 최종 16명(근속기간 평균 11년 이상인 디자인학 교수 4 명, 공학교수 4 명, 이학 교수 4 명, 교육학 교수 4 명)의 델파이 패널 을 구성하여 진행하였다. 조사기간은 2012년 5월 1 일부터 6 월 25 일까지 3 차에 걸쳐 진행되었다. 1 차 조사는 개방형 질문지로 5월 1일부터 5월 20 일까지 실시되었으며, 2 차 조사는 1 차 조사 분석 후 내용을 범주화 및 코드화하여 구조화된 설문 지 형태로 재구성하여 5월 27일부터 6월 10일까 지 조사하였다. 3 차 조사는 2 차 조사에서 확인된 내용들 중에서 추가문항의 개발여부를 판단한 후, 최종적인 평정점수(평균 및 표준편차)를 보여 준 다음 각각의 질문 항목들에 대해 재평가하는 형태로 이루어졌고 6월 17일부터 6월 25일까지 조사하였다.

\section{2. 조사도구}

본 연구의 목적을 위하여 디자인 사고에 대한 전문가 의견 수렴으로서 델파이 조사 문항을 개 발하였다.

델파이 조사방법은 특정 전문직이 수행하는 특 정의제의 우선순위를 평가하는 지표 혹은 대안을 개발하는 방법으로서, 전문가 집단 간의 특정한 문제에 대한 사회적 합의(social consensus)를 도 출하는데 효과적인 방법으로 잘 알려져 있다(박 성미, 2008; Dawson \& Brucker, 2001). 일반적으 로 델파이 조사방법에서는 다단계의 연구절차 (multistage process)를 통해 특정 의제에 대한 전문가 패널들 간의 민주적 합의를 도출해 내는 방법으로 사용된다(Hassen, Keeney \& McKenna, 2000).
따라서 1 차 델파이 조사 질문지는 개방형 질문 으로 구성하였으며, 각각의 요인들에 대하여 전 문가 패널들이 자신의 의견을 1 순위에서 3 순위로 나누어 자유롭게 기입하도록 하였다. 1순위에서 3 순위별로 기재하도록 한 것은 전문가 패널들의 의견 일치 및 1 순위 항목에 대한 타당성을 확보 하기 위한 절차로 사용되었다(Hassen, Keeney \& McKenna, 2000). 세부적인 내용으로는 디자인 교 과교육을 중심으로 (1) 예술, 공학, 과학, 사회과 학 분야 활동을 위하여 요구되는 직관적 사고는 무엇이라고 생각합니까? (2) 예술, 공학, 과학, 사 회과학 분야 활동을 위하여 요구되는 논리적 사 고는 무엇이라고 생각합니까? (3) 예술, 공학, 과 학, 사회과학 분야 활동을 위하여 요구되는 주관 적 사고는 무엇이라고 생각합니까? (4) 예술, 공 학, 과학, 사회과학 분야 활동을 위하여 요구되는 객관적 정보의 활용은 무엇이라고 생각합니까? 등이다.

2 차 델파이 조사 질문지는 1 차 조사결과를 토 대로 하였으며, 각 기관별 델파이 문항을 개발하 였다. 2차는 1 차 개방형 질문형태를 7점 리커트 척도(매우 중요함=7 전혀 중요하지 않음=1)로 '중요도'를 측정하였다.

3 차 델파이 조사 질문지는 2 차 델파이 조사결 과를 토대로 구성하였다. 2차로 수집된 자료에 대한 기본 통계값을 제시하고, 각 항목별 '중요 도'를 7점 리커트 척도로 측정하였다.

\section{3. 자료 분석방법}

본 연구의 목적을 위하여 먼저, 수집된 자료는 빈도, 백분율, 평균 및 표준편차 등의 기술통계분 석을 하였다.

1 차 델파이 조사에서는 본 연구의 주제와 관련 하여 각각의 요인별로 응답된 자료들을 토대로 1 3순위까지의 의견에 관한 빈도를 구하였다. 이 를 다시 빈도총계와 가중총점으로 나누어 집계한 다음, 가중총점을 표준점수화(Z점수)하여 각각의 
문항들이 가지는 중요도를 $\pm 0.5 \mathrm{SD}$ 를 기준으로 하여, $\pm 0.5 \mathrm{SD}$ 이내의 편차값을 보이는 변수만을 측정의 대상으로 삼았다.

2 차 델파이 조사에서는 1 차 조사에서 도출된 문항들에 대하여 델파이 패널들이 각각의 변수들 에 대하여 '중요도'(매우 중요함=7 전혀 중요하 지 않음=1)에 대한 평정을 하도록 하였으며, 각 문항의 평균값과 표준편차, 사분위값과 관련한 기술통계치를 얻는 방식으로 분석하였다. 또한 의견합의 점검으로 켄달의 부합도 계수(Kendall's coefficient of concordance)인 W검정을 통해 패 널들의 응답 일치도와 각 문항들의 평균 순위를 구하는 방식으로 비모수검정(Kendall's W)을 실 시하였다. 이는 조사결과에 대한 타당도 확인 작 업으로 Kendall's W검정결과가 통계적으로 유의 할 경우 $(\mathrm{p}<.05)$ 귀무가설이 기각되어 각 문항들에 대한 패널들 간에 의견은 일치하는 것으로 해석 하였다.

3 차 델파이 조사에서도 2차 조사와 동일하게 Kendall's W의 검정으로 분석하는 방식을 사용 하였다. 그리고 2차 조사결과를 재확인하기 위하 여, 패널들에게 2 차 평정결과를 보여주고, 패널들 이 자신의 응답결과와 다른 패널들의 응답결과를 비교하여 본 다음, 자신의 의견을 재평가하는 방 식으로 진행하였다.

\section{IV. 연구 결과}

\section{1. 직관적 사고에 대한 델파이 분석}

예술, 과학, 공학, 사회과학 분야에서 공통으로 요구되는 직관적 사고의 요인을 알아보기 위하여 1 차, 2 차, 3 차에 걸쳐 전문가 델파이 분석을 하였 다(<표 2> 참조).

직관적 사고에 대한 1 차 델파이 조사에서 회수 된 응답내용을 범주화 한 결과, 총 9 개의 속성을 분류할 수 있었다. 이 중 표준점수(Z값 $\pm 0.5 \mathrm{SD}$ ) 를 기준으로 최종 분류한 항목들은 다음과 같이 7 개로 정리되었다. 2 차 조사는 1 차 조사에서 도 출된 문항들에 대하여 전문가들이 생각하는 중요 도를 평정하는 방식으로 진행되었다. 그 결과, 2 차 결과에서는 비모수검정(Kendall's W)을 통해, 전문가들이 생각하는 직관적 사고의 내용을 정리 하였다(Kendall's $\mathrm{W}=.045, \mathrm{p}>.01)$. 조사결과, 뜻 밖의 가능성을 추구하는 것(5.00), 복잡한 실제 현상과 맞서는 것(4.90), 새로운 형태의 기술로 적용 가능성을 추구(4.70), 콘텐츠 기획(4.70) 등의 순으로 나타났다. 3 차 조사는 2차에서 나온 응답 결과를 중심으로, 전문가들에게 2차 조사의 결과 들을 보여주고, 중요도를 체크하는 방식으로 진 행되었다. 비모수 검정(Kendall's W)결과, 전문 가들의 의견은 대체로 일치하지 않는 것으로 나 타났다(Kendall's $\mathrm{W}=.253, \mathrm{p}>.01$ ). 그러나 설문문

<표 2> 예술, 공학, 과학, 사회과학 분야에서 공통으로 요구되는 직관적 사고

\begin{tabular}{l|rr|r|r|r|r}
\hline \multicolumn{1}{c|}{ 1차 델파이 결과 } & \multicolumn{5}{c}{ 중요도 } \\
\cline { 2 - 7 } & 1차 & 2차 & 3차 & 총계 & 총점 & Z값 \\
\hline \hline 1. 새로운 형태의 기술로 적용가능성 추구 & 3 & 2 & 1 & 6 & 11 & 2.01 \\
2. 미지의 것에 대한 탐색 & 3 & 1 & 3 & 7 & 10 & 1.75 \\
3. 기술을 활용한 어플리케이션 구상 & 3 & & & 3 & 6 & 1.46 \\
4. 새로움의 문제 & 3 & & & 3 & 6 & 1.46 \\
5. 복잡한 실제 현상과 맞서는 것 & & 2 & & 2 & 4 & 1.20 \\
6. 뜻 밖의 가능성을 추구하는 것 & 1 & & 1 & 2 & 4 & 1.20 \\
7. 콘텐츠 기획 & & 2 & & 2 & 4 & 1.20 \\
\hline 합계 & 13 & 7 & 5 & 25 & 45 & \\
\hline
\end{tabular}

* 빈도총계=제 1순위빈도+제 2순위빈도+제 3순위빈도에 대한 단순합계

가중총점 $=$ 각 항목별 $(1$ 순위빈도×3), (2순위빈도 $\times 2)$, (3순위빈도 $\times 1)$ 을 합한 총 점수 


\begin{tabular}{|c|c|c|c|c|}
\hline \multirow{2}{*}{ 2차 델파이 결과 } & \multirow{2}{*}{$\mathrm{M}$} & \multirow{2}{*}{ SD } & \multicolumn{2}{|c|}{ 백분위수 } \\
\hline & & & 25 & 75 \\
\hline 1. 새로운 형태의 기술로 적용가능성 추구 & 6.40 & .55 & 6.00 & 7.00 \\
\hline 2. 미지의 것에 대한 탐색 & 6.00 & 1.00 & 5.00 & 7.00 \\
\hline 3. 기술을 활용한 어플리케이션 구상 & 5.20 & 1.10 & 4.50 & 6.00 \\
\hline 4. 새로움의 문제 & 5.80 & 1.30 & 4.50 & 7.00 \\
\hline 5. 복잡한 실제 현상과 맞서는 것 & 6.40 & .89 & 5.50 & 7.00 \\
\hline 6. 뜻 밖의 가능성을 추구하는 것 & 6.60 & .55 & 6.00 & 7.00 \\
\hline 7. 콘텐츠 기획 & 6.40 & .55 & 6.00 & 7.00 \\
\hline
\end{tabular}

$\mathrm{N}=16$, Kendall's $\mathrm{W}=.045$ Chi-Square $=0.897 \mathrm{df}=11, \mathrm{sig}=.925$

\begin{tabular}{l|c|c|c|c|c}
\multicolumn{1}{c|}{ 3차 델파이 결과 } & \multirow{2}{*}{$\mathrm{M}$} & \multirow{2}{*}{$\mathrm{SD}$} & \multicolumn{2}{|c|}{ 백분위수 } & \multirow{2}{*}{ 평균 } \\
\cline { 4 - 5 } & & & 25 & 75 & 순위 \\
\hline \hline 1. 뜻 밖의 가능성을 추구하는 것 & 6.87 & .35 & 7.00 & 7.00 & 5.44 \\
2. 새로운 형태의 기술로 적용가능성 추구 & 6.87 & .35 & 7.00 & 7.00 & 5.31 \\
3. 콘텐츠 기획 & 6.62 & .51 & 6.00 & 7.00 & 4.81 \\
4. 복잡한 실제 현상과 맞서는 것 & 6.37 & .91 & 5.25 & 7.00 & 4.25 \\
5. 미지의 것에 대한 탐색 & 6.12 & .83 & 5.25 & 7.00 & 3.38 \\
6. 새로움의 문제 & 5.87 & .64 & 5.25 & 6.00 & 2.88 \\
7. 기술을 활용한 어플리케이션 구상 & 5.12 & 1.12 & 4.00 & 6.00 & 1.94 \\
\hline
\end{tabular}

$\mathrm{N}=16$, Kendall's $\mathrm{W}=.253$ Chi-Square $=8.091, \mathrm{df}=4, \mathrm{sig}=.088$

항 중에 가장 높은 평균 순위를 보이는 것은 뜻 밖의 가능성을 추구하는 것(5.44), 새로운 형태의 기술로 적용 가능성 추구(5.31), 콘텐츠 기획 (4.81), 복잡한 실제 현상과 맞서는 것(4.25) 등의 순으로 나타나, 2차 결과와는 다소 차이가 있는 결과가 도출되었다.

\section{2. 논리적 사고에 대한 델파이 분석}

예술, 과학, 공학, 사회과학 분야에서 공통으로 요구되는 논리적 사고의 요인을 알아보기 위하여 1 차, 2 차, 3 차에 걸쳐 전문가 델파이 분석을 하였 다(<표 3> 참조).

논리적 사고에 대한 1차 델파이 조사에서 회수 된 응답내용을 범주화 한 결과, 총 10 개의 속성 을 분류할 수 있었다. 이 중 표준점수( $\mathrm{Z}$ 값 $\pm 0.5 \mathrm{SD})$ 를 기준으로 최종 분류한 항목들은 다음 과 같이 7 개로 정리되었다. 2차 조사는 1 차 조사 에서 도출된 문항들에 대하여 전문가들이 생각하 는 중요도를 평정하는 방식으로 진행되었다. 그 결과, 2차 결과에서는 비모수검정(Kendall's W)을
통해, 전문가들이 생각하는 논리적 사고의 내용 을 정리하였다(Kendall's W=.380, p<.01). 조사결 과, 추론과 검증을 반복적으로 실행(5.65), 인공지 능(4.75), 깊고 세심하며 개방적인 관찰(4.40), 의 사결정 시스템(4.00) 등의 순으로 나타났다. 3차 조사는 2차에서 나온 응답결과를 중심으로, 전문 가들에게 2차 조사의 결과들을 보여주고, 중요도 를 체크하는 방식으로 진행되었다. 비모수 검정 (Kendall's W)결과, 전문가들의 의견은 대체로 일치하는 것으로 나타났다(Kendall's W=.362, $\mathrm{p}<.01)$. 설문문항 중에 가장 높은 평균 순위를 보 이는 것은 추론과 검증을 반복적으로 실행(5.55), 인공지능(4.55), 깊고 세심하며 개방적인 관찰 (4.45), 의사결정 시스템(4.20) 순으로 나타나, 2차 결과와 거의 동일한 결과가 도출되었다.

\section{3. 주관적 사고에 대한 델파이 분석}

예술, 과학, 공학, 사회과학 분야에서 공통으로 요구되는 주관적 사고의 요인을 알아보기 위하여 1 차, 2 차, 3 차에 걸쳐 전문가 델파이 분석을 하였 
<표 3> 예술, 공학, 과학, 사회과학 분야에서 공통으로 요구되는 논리적 사고

\begin{tabular}{|c|c|c|c|c|c|c|}
\hline \multirow{2}{*}{ 1차 델파이 결과 } & \multicolumn{6}{|c|}{ 중요도 } \\
\hline & 1차 & 2차 & 3차 & 총계 & 총점 & Z값 \\
\hline 1. 인공지능 & 3 & 3 & & 6 & 15 & 0.77 \\
\hline 2. 알고리즘 기술 & 5 & 4 & 2 & 11 & 25 & 1.90 \\
\hline 3. 추론과 검증을 반복적으로 실행 & & 1 & & 1 & 2 & -0.69 \\
\hline 4. 아이디어를 행위 체계로 전환 & 1 & & 5 & 6 & 8 & -0.02 \\
\hline 5. 의사결정 시스템 & 1 & & & 1 & 3 & -0.58 \\
\hline 6. 시스템 설계 & & 1 & & 1 & 2 & -0.69 \\
\hline 7. 깊고 세심하며 개방적인 관찰 & & & 2 & 2 & 2 & -0.69 \\
\hline 합계 & 10 & 9 & 9 & 28 & 57 & \\
\hline
\end{tabular}

* 빈도총계=제 1순위빈도+제 2순위빈도+제 3순위빈도에 대한 단순합계

가중총점=각 항목별 (1순위빈도×3), (2순위빈도 $\times 2)$, (3순위빈도 $\times 1)$ 을 합한 총 점수

\begin{tabular}{|c|c|c|c|c|c|}
\hline \multirow{2}{*}{ 2차 델파이 결과 } & & \multirow{2}{*}{\multicolumn{2}{|c|}{ SD }} & \multicolumn{2}{|c|}{ 백분위수 } \\
\hline & $\mathrm{M}$ & & & 25 & 75 \\
\hline 1. 인공지능 & 6.20 & \multicolumn{2}{|l|}{1.033} & 5.75 & 7.00 \\
\hline 2. 알고리즘 기술 & 5.00 & \multicolumn{2}{|c|}{0.943} & 4.00 & 5.25 \\
\hline 3. 추론과 검증을 반복적으로 실행 & 6.70 & \multicolumn{2}{|c|}{0.483} & 6.00 & 7.00 \\
\hline 4. 아이디어를 행위 체계로 전환 & 5.60 & \multicolumn{2}{|l|}{1.265} & 4.00 & 7.00 \\
\hline 5. 의사결정 시스템 & 6.00 & \multicolumn{2}{|c|}{0.943} & 5.75 & 7.00 \\
\hline 6. 시스템 설계 & 5.90 & \multicolumn{2}{|c|}{0.994} & 5.00 & 7.00 \\
\hline 7. 깊고 세심하며 개방적인 관찰 & 6.20 & \multicolumn{2}{|l|}{0.632} & 6.00 & 7.00 \\
\hline $\mathrm{N}=16, \quad$ Kendall's $\quad W=.380$, & Chi-Square $=23.200$, & \multirow{2}{*}{\multicolumn{3}{|c|}{ Sig $=.001$}} & \\
\hline \multirow{2}{*}{ 3차 델파이 결과 } & \multirow{2}{*}{$\mathrm{M}$} & \multirow{2}{*}{ SD } & & 백분위수 & \multirow{2}{*}{$\begin{array}{l}\text { 평균 } \\
\text { 순위 }\end{array}$} \\
\hline & & & 25 & 75 & \\
\hline 1. 추론과 검증을 반복적으로 실행 & 6.70 & 0.675 & 6.75 & 7.00 & 5.55 \\
\hline 2. 인공지능 & 6.10 & 0.994 & 5.75 & 7.00 & 4.55 \\
\hline 3. 깊고 세심하며 개방적인 관찰 & 6.30 & 0.675 & 6.00 & 7.00 & 4.45 \\
\hline 4. 의사결정 시스템 & 6.10 & 0.738 & 5.75 & 7.00 & 4.20 \\
\hline 5. 아이디어를 행위 체계로 전환 & 5.90 & 1.101 & 5.00 & 7.00 & 3.75 \\
\hline 6. 시스템 설계 & 5.80 & 1.135 & 4.75 & 7.00 & 3.50 \\
\hline 7. 알고리즘 기술 & 5.00 & 0.943 & 4.00 & 5.25 & 2.00 \\
\hline Kendall's $\quad W=.362$, & Chi-Square $=22.049$, & $\mathrm{df}=6$, & Sig $=$. & & \\
\hline
\end{tabular}

다(<표 4> 참조). 주관적 사고에 대한 1 차 델파이 조사에서 회수된 응답내용을 범주화 한 결과, 총 12 개의 속성을 분류할 수 있었다. 이 중 표준점 수(Z값 $\pm 0.5 \mathrm{SD})$ 를 기준으로 최종 분류한 항목들 은 다음과 같이 9 개로 정리되었다. 2차 조사는 1 차 조사에서 도출된 문항들에 대하여 전문가들이 생각하는 중요도를 평정하는 방식으로 진행되었 다. 그 결과, 2차 결과에서는 비모수검정 (Kendall's W)을 통해, 전문가들이 생각하는 주관 적 사고의 내용을 정리하였다(Kendall's $\mathrm{W}=.367$, $\mathrm{p}<.001)$. 조사결과, 사용자 경험 측정 $(7.25)$, 사용 자 만족도 평가(6.21), 인간의 구매심리(6.00), 사 용자 요구사항 분석(5.63), 사용자 인터페이스 설 계(4.96), 인간의 반응행동(4.58) 등의 순으로 나타 났다. 3 차 조사는 2 차에서 나온 응답결과를 중심 으로, 전문가들에게 2차 조사의 결과들을 보여주 고, 중요도를 체크하는 방식으로 진행되었다. 비 모수 검정(Kendall's W)결과, 전문가들의 의견은 대체로 일치하는 것으로 나타났다(Kendall's $W=.260$, $\mathrm{p}<.01)$. 설문문항 중에 가장 높은 평균 순위를 보 
<표 4> 예술, 공학, 과학, 사회과학 분야에서 공통으로 요구되는 주관적 사고

\begin{tabular}{l|r|r|r|r|r|r}
\hline \multicolumn{1}{c}{ 1차 델파이 결과 } & \multicolumn{5}{c}{ 중요도 } \\
\cline { 2 - 7 } & 1차 & 2차 & 3차 & 총계 & 총점 & Z값 \\
\hline \hline 1. 인간의 구매 심리 & 2 & 4 & 2 & 8 & 16 & 2.07 \\
2. 사용자 만족도 평가 & 4 & & 4 & 8 & 16 & 2.07 \\
3. 사용자 경험 측정 & 2 & 3 & 2 & 7 & 14 & 1.70 \\
4. 사용자 요구사항 분석 & 2 & & & 2 & 6 & 0.21 \\
5. 사용자인터페이스 설계 & & 2 & & 2 & 4 & -0.16 \\
6. 감성 및 정서적 이해 & 1 & & & 1 & 3 & -0.35 \\
7. 인간행동의 분석 & & 1 & 1 & 2 & 3 & -0.35 \\
8. 인간 본질에 대한 이해 & 1 & & & 1 & 3 & -0.35 \\
9. 인간의 반응 행동 & 1 & & & 1 & 3 & -0.35 \\
\hline 합계 & 13 & 10 & 9 & 32 & 68 & \\
\hline
\end{tabular}

* 빈도총계=제 1순위빈도+제 2순위빈도+제 3순위빈도에 대한 단순합계

가중총점=각 항목별 $(1$ 순위빈도 $\times 3),(2$ 순위빈도 $\times 2)$, (3순위빈도 $\times 1)$ 을 합한 총 점수

\begin{tabular}{l|c|c|c|c}
\multicolumn{1}{c}{ 2차 델파이 결과 } & \multirow{2}{*}{$\mathrm{M}$} & \multirow{2}{*}{$\mathrm{SD}$} & \multicolumn{2}{c}{ 백분위수 } \\
\cline { 4 - 5 } & & & 25 & 75 \\
\hline \hline 1. 인간의 구매 심리 & 6.25 & .754 & 6.00 & 7.00 \\
2. 사용자 만족도 평가 & 6.33 & .985 & 6.00 & 7.00 \\
3. 사용자 경험 측정 & 6.67 & .651 & 6.25 & 7.00 \\
4. 사용자 요구사항 분석 & 6.17 & .577 & 6.00 & 6.75 \\
5. 사용자인터페이스 설계 & 6.00 & .603 & 6.00 & 6.00 \\
6. 감성 및 정서적 이해 & 4.92 & 1.240 & 4.00 & 6.00 \\
7. 인간행동의 분석 & 5.42 & .996 & 5.00 & 6.00 \\
8. 인간 본질에 대한 이해 & 5.83 & .835 & 5.00 & 6.75 \\
9. 인간의 반응 행동 & 5.83 & .835 & 5.00 & 6.75 \\
\hline
\end{tabular}

$\mathrm{N}=16$, Kendall's $\mathrm{W}=.367$ Chi-Square $=35.193 \mathrm{df}=8$, sig $=.000$

\begin{tabular}{|c|c|c|c|c|c|}
\hline \multirow{2}{*}{ 3차 델파이 결과 } & \multirow{2}{*}{$\mathrm{M}$} & \multirow{2}{*}{ SD } & \multicolumn{2}{|c|}{ 백분위수 } & \multirow{2}{*}{$\begin{array}{l}\text { 평균뉜 } \\
\text { 슁 }\end{array}$} \\
\hline & & & 25 & 75 & \\
\hline 1. 사용자 경험 측정 & 6.54 & .660 & 6.00 & 7.00 & 6.88 \\
\hline 2. 사용자 만족도 평가 & 6.23 & .832 & 5.50 & 7.00 & 6.12 \\
\hline 3. 인간의 구매 심리 & 6.15 & .689 & 6.00 & 7.00 & 5.81 \\
\hline 4. 사용자 요구사항 분석 & 6.15 & .376 & 6.00 & 6.00 & 5.69 \\
\hline 5. 인간의 반응 행동 & 6.00 & .707 & 5.50 & 6.50 & 5.12 \\
\hline 6. 인간 본질에 대한 이해 & 5.62 & 1.044 & 5.00 & 6.50 & 4.35 \\
\hline 7. 사용자인터페이스 설계 & 5.77 & .599 & 5.00 & 6.00 & 4.35 \\
\hline 8. 인간행동의 분석 & 5.54 & 1.050 & 5.00 & 6.50 & 3.96 \\
\hline 9. 감성 및 정서적 이해 & 5.08 & 1.188 & 4.00 & 6.00 & 2.73 \\
\hline
\end{tabular}

이는 것은 사용자 경험 측정(6.88), 사용자 만족 도 평가(6.12), 인간의 구매심리(5.81), 사용자 요 구사항 분석(5.69), 인간의 반응 행동(5.12), 사용 자 인터페이스 설계(4.35)의 순으로 나타나, 2차 결과와는 거의 유사한 결과가 도출되었다.

\section{4. 객관적 정보에 대한 델파이 분석}

예술, 과학, 공학, 사회과학 분야에서 공통으로 요구되는 객관적 정보의 요인을 알아보기 위하여 1 차, 2 차, 3 차에 걸쳐 전문가 델파이 분석을 하였 다(<표 5> 참조). 객관적 정보에 대한 1 차 델파이 
조사에서 회수된 응답내용을 범주화 한 결과, 총 9개의 속성을 분류할 수 있었다. 이 중 표준점수
(Z값 $\pm 0.5 \mathrm{SD})$ 를 기준으로 최종 분류한 항목들은 다음과 같이 8 개로 정리되었다.

<표 5> 예술, 공학, 과학, 사회과학 분야에서 공통으로 요구되는 객관적 정보의 활용

\begin{tabular}{|c|c|c|c|c|c|c|}
\hline \multirow{2}{*}{1 차 델파이 결과 } & \multicolumn{6}{|c|}{ 중요도 } \\
\hline & 1차 & 2차 & 3차 & 총계 & 총점 & Z값 \\
\hline 1. 시장분석 등을 통한 유사 제품 파악 & & 1 & 1 & 2 & 3 & -0.46 \\
\hline 2. 정보관리시스템 & 2 & & 1 & 3 & 7 & 1.37 \\
\hline 3. 시뮬레이션(컴퓨터 그래픽스, 물리기반 시뮬레이션 등) & 1 & 1 & & 2 & 5 & 0.15 \\
\hline 4. 기획을 위해 관련이론(이종학문분야) 검색 & 1 & & 2 & 3 & 5 & -1.07 \\
\hline 5. 해당 분야의 원천지식 및 전문지식 & 3 & & 4 & 7 & 13 & 1.98 \\
\hline 6. 지식경영 & 3 & 5 & 2 & 10 & 21 & 0.00 \\
\hline 7. 생산 프로세스 & & 2 & & 2 & 4 & 1.52 \\
\hline 8. 정보 교환 및 공유 & & 1 & & 1 & 2 & 0.76 \\
\hline 합계 & 10 & 10 & 10 & 30 & 60 & \\
\hline
\end{tabular}

* 빈도총계=제 1순위빈도+제 2순위빈도+제 3순위빈도에 대한 단순합계

가중총점=각 항목별 (1순위빈도×3), (2순위빈도×2), (3순위빈도×1)을 합한 총 점수

\begin{tabular}{|c|c|c|c|c|}
\hline \multirow{2}{*}{ 2차 델파이 결과 } & \multirow{2}{*}{ M } & \multirow{2}{*}{$\mathrm{SD}$} & \multicolumn{2}{|c|}{ 백분위수 } \\
\hline & & & 25 & 75 \\
\hline 1. 시장분석 등을 통한 유사 제품 파악 & 4.50 & 1.354 & 3.75 & 6.00 \\
\hline 2. 정보관리시스템 & 6.30 & .675 & 6.00 & 7.00 \\
\hline 3. 시뮬레이션(컴퓨터 그래픽스, 물리기반 시뮬레이션 등) & 6.10 & .568 & 6.00 & 6.25 \\
\hline 4. 기획을 위해 관련이론(이종학문분야) 검색 & 4.90 & 1.101 & 4.00 & 5.25 \\
\hline 5. 해당 분야의 원천지식 및 전문지식 & 5.50 & 1.080 & 4.75 & 6.25 \\
\hline 6. 지식경영 & 4.30 & .949 & 3.75 & 5.00 \\
\hline 7. 생산 프로세스 & 5.30 & 1.059 & 5.00 & 6.00 \\
\hline 8. 정보 교환 및 공유 & 5.40 & 1.430 & 4.00 & 7.00 \\
\hline
\end{tabular}

\begin{tabular}{l|c|c|c|c|c}
\hline \multicolumn{1}{c|}{ 3차 델파이 결과 } & \multirow{2}{*}{$\mathrm{M}$} & \multirow{2}{*}{$\mathrm{SD}$} & \multicolumn{2}{|c|}{ 백분위수 } & \multirow{2}{*}{ 평균 } \\
\cline { 4 - 5 } 순위
\end{tabular}

$\mathrm{N}=16$, Kendall's $\mathrm{W}=.352$ Chi-Square $=8.910, \mathrm{df}=4$, sig $=.089$

2차 조사는 1 차 조사에서 도출된 질문문항들에 대하여 전문가들이 생각하는 중요도를 평정하는 방식으로 진행되었다. 그 결과, 2차 결과에서는 비모수검정(Kendall's W)을 통해, 전문가들이 생각
하는 직관적 사고의 내용을 정리하였다(Kendall's $\mathrm{W}=.054, \mathrm{p}>.001)$. 조사결과, 정보관리 시스템(6.60), 시뮬레이션(6.20), 정보교환 및 공유(5.00), 생산 프로세스(4.70), 해당 분야의 원천 지식 및 전문 
지식(4.60), 기획을 위한 관련 이론 검색(3.65) 등 의 순으로 나타났다.

3 차 조사는 2차에서 나온 응답결과를 중심으 로, 전문가들에게 2차 조사의 결과들을 보여주고, 중요도를 체크하는 방식으로 진행되었다. 비모수 검정(Kendall's W)결과, 전문가들의 의견은 대체 로 일치하지 않는 것으로 나타났다(Kendall's $\mathrm{W}=.352, \mathrm{p}>.01)$. 그러나 설문문항 중에 가장 높은 평균 순위를 보이는 것은 정보관리 시스템(7.20), 시뮬레이션(7.05), 생산 프로세스(5.30), 해당 분야 의 원천 지식 및 전문 지식(4.75), 정보교환 및 공유(4.75)의 순으로 나타나, 2 차 결과와는 다소 차이가 있는 결과가 도출되었다.

\section{$\mathrm{V}$. 논의 및 제언}

본 연구는 다학제 교육의 실천방안이 되는 교 역지대로서 디자인 사고를 탐색하기 위하여 델파 이 연구를 하였다. 이에 나타난 연구결과는 아래 와 같다.

첫째, 예술, 과학, 공학, 사회과학 분야에서 공 통으로 요구되는 직관적 사고에 대한 전문가의 의견은 일치하지 않는 것으로 나타났다. 그러나 전문가들이 제시한 3 차 결과를 중심으로 볼 때, 직관적 사고에 뜻밖의 가능성을 추구, 새로운 형 태의 기술로 적용 가능성 추구, 콘텐츠 기획, 복 잡한 실제 현상에 맞서는 것 등의 내용을 포함하 고 있다.

이러한 결과는 직관적 사고에 대하여 학문 분 야별 관점이 다양하다는 것을 의미한다. 이는 직 관이라는 그 자체가 곽은혜와 이은경(2011), 윤호 창(2004)의 연구에서 제안한 것과 마찬가지로 현 상학적 관점을 지니고 있는 이유일 것이다. 그러 므로 다학제 교육을 위하여 직관적 사고는 추후 연구를 통해 '교역지대'로서 더욱 면밀히 분석되 어야 할 변인임을 알 수 있다. 그러나 다학제의 연결, 통합에 있어 직관적 사고의 필요성에 대한
원천적 질문에 대하여 각 학문분야별 전문가들은 동일한 견해를 밝히고 있었다(3차 결과를 중심으 로). 이는 직관적 사고가 다학제의 이론적 근거로 서 타당한 설명을 하고 있음을 의미한다.

둘째, 예술, 과학, 공학, 사회과학 분야에서 공 통으로 요구되는 논리적 사고에 대한 전문가의 의견은 대체로 일치하는 것으로 나타났다. 2차 조사와 3 차 조사결과 거의 동일한 항목(추론과 검증을 반복적으로 실행, 인공지능, 깊고 세심하 며 개방적인 관찰, 의사결정 시스템)으로 분류되 었다. 이러한 결과는 논리적 사고가 각 학문분야 별로 고유한 개별성이 존재함에도 불구하고 다학 제의 근간으로서 적용 가능성을 구체적으로 시사 하고 있다고 볼 수 있다. 특히 논리적 사고는 모 든 학문의 알고리즘 측면에서 인과관계를 기본으 로 분석적이며 체계적인 문제해결 방식으로 수용 될 수 있음을 의미한다.

이는 인간의 과학적 활동과 예술적 활동은 궁 극적으로 목적이 같으며 그 발현과정이 유사하다 고 하는 이대현(2008)의 연구를 지지하는 것으로 볼 수 있다. 또한 수학, 과학과 같은 기능 및 기 술적인 학문에 직관적 요소가 가미되어질 때 창 의적 문제해결에 더 효과적으로 도달할 수 있다 는 다학제 형태의 가능성을 시사하는 이순종 외 (2007)의 연구, 윤호창(2004)의 연구를 지지하는 것으로 볼 수 있다.

셋째, 예술, 과학, 공학, 사회과학 분야에서 공 통으로 요구되는 주관적 사고에 대한 전문가의 의견도 대체로 일치하는 것으로 나타났다. 2차 조사와 3 차 조사결과 거의 유사한 항목(사용자 경험 측정, 사용자 만족도 평가, 인간의 구매심 리, 사용자 요구사항 분석, 인간의 반응행동, 사 용자 인터페이스 설계)으로 분류되었다.

이러한 결과는 모든 학문분야가 그 접근의 방 식을 달리할 뿐, 인간을 주된 대상으로 학문의 이론을 설명하고 있다는 강정하와 최인수(2006), 윤주현(2009), 이순종 외(2006) 등의 연구결과를 지지하는 것으로 볼 수 있다. 그러므로 주관적 
사고는 전문가들 간에 공유할 만한 '교역지대'로 서 수용될 수 있음을 알 수 있다.

넷째, 예술, 과학, 공학, 사회과학 분야에서 공 통으로 요구되는 객관적 정보활용에 대한 전문가 의 의견은 일치하지 않는 것으로 나타났다. 이러 한 결과는 각 학문분야에 대한 객관적 정보 그 자체가 상이하다는 점을 반영한 것으로 볼 수 있 다. 그러므로 전문가들 간에 다양한 의견이 제시 되는 것은 아마도 당연한 귀결로 보여진다. 그러 나 다학제의 근간으로서 객관적 정보활용에 대한 원천적 질문에 전문가들은 객관적 정보활용의 중 요성을 동일하게 인지하고 있는 것으로 나타났 다. 그러므로 객관적 정보활용 역시 다학제의 이 론적 근간으로서 적절한 설명을 하는 변인으로 볼 수 있다.

이상의 본 연구결과를 종합해 볼 때, 다학제 교육을 위한 이론적 근간으로서 디자인 사고는 직관적 사고, 논리적 사고, 주관적 사고, 객관적 정보의 활용 등이 포함될 수 있다는 것을 알 수 있다.

더 나아가 직관적 사고와 객관적 정보의 활용 은 각 고유 영역에 대한 주체를 부각시키되, 논 리적 사고와 주관적 사고에 대한 종합 혹은 통합 적 접근을 통해 '교역지대' 즉 공통영역을 더욱 확보함으로써 효과적인 다학제 접근의 가능성을 도모할 수 있을 것으로 생각한다. 이는 다학제란 '교역지대', 곧 논리적 협상을 통해 도출된다는 오헌석 외(2012)의 연구, 정연숙, 김현경(2011)의 연구를 지지하는 것으로 볼 수 있다.

또한 예술, 과학, 공학, 사회과학 분야에서 공 통으로 요구되는 직관적 사고, 논리적 사고, 주관 적 사고, 객관적 정보활용 등의 하위 항목들(직관 적 사고, 7항목; 논리적 사고, 7항목; 주관적 사 고, 9항목; 객관적 사고, 8항목)은 바로 다학제간 연결, 통합을 위한 개념적 틀로 적용할 수 있다. 이는 강정하, 최인수(2008)의 연구, 정영기(2012) 의 연구 등에서 다학제의 실천 방안으로서 '인간. 가치·창의성'이라는 키워드만을 제공하는 기존의
연구결과를 벗어나 진일보한 학문적 자료를 제공 해줄 수 있을 것으로 기대된다.

이상의 본 연구의 결과를 토대로 한계점 및 제 언을 하면 다음과 같다.

첫째, 본 연구에서 도출된 디자인 사고는 전문 가 패널에 의하여 확인된 것이지만 전문가 패널 이 디자인, 이학, 공학, 교육학 분야의 전문가로 구성되었다는 것이 한계점이 될 수 있다. 추후 보다 포괄적인 학제 분야(경영학, 의학, 사회과학) 를 포함하여 디자인 사고에 대한 타당성을 추가 적으로 확보할 필요가 있다.

둘째, 본 연구에서 도출된 디자인 사고 구인은 향후 다학제 교육의 기초 자료로서 제공될 수 있 을 것이다. 그러나 본 연구는 문헌연구를 토대로 전문가 패널에게 디자인 사고의 네 가지 하위요 인을 반구조화된 방식으로 제안하여 결과를 도출 하였다. 그러나 추후 연구에서 비구조화된 자유 기술방식으로 디자인 사고를 더 면밀히 탐색해 볼 필요가 있다. 이러한 경험적 타당성을 확보하 는 연구결과의 축적을 통해 본 연구에서 확인된 디자인 사고 구인은 대학에서 다학제 교육을 비 롯하여 기업에서 다학제 협업 등 여러 방면에서 효과적으로 활용될 수 있을 것이다.

셋째, 본 연구에서 확인된 결과는 다학제 교육 실시와 관련된 타당성을 평가할 수 있는 근간이 될 수 있다. 덧붙여 본 연구에서 확인된 디자인 사고는 추후 다학제 교육을 이수한 대학생으로 하여금 그 핵심역량으로서 타당성이 있는지를 경 험적으로 검토하며 이와 아울러 디자인 사고를 측정하는 도구 개발에 응용될 수 있을 것이다.

\section{참고 문헌}

곽은혜 · 이은경(2011). 키에르케고르의 주관적 지 식과 도덕 교육, 도덕교육연구 23(1), 153 182.

강성종 - 김용욱(2010). 한국 특수교육에서의 학문

융합 사고적 접근, 특수교육학연구 44(4), 19 42. 강정하 - 최인수(2006). 창의적 문제해결력 프로그 
램이 대학생의 창의적 문제해결 성향과 수행능 력에 미치는 효과. 교육심리연구 20(3), 679 701. 강현석 - 방기용(2012). 교육과정 재구성 요인 분 석을 위한 탐색, 수산해양교육연구 24(1), 123 135.

김유신 · 윤상근 · 안호영(2012). 공학소양과 인문 교육의 통섭, 수산해양교육연구 24(2), 346 354.

노상우 - 안동순(2012). 학문융합 관점에서 본 현 대교육의 이론적-실천적 변화 모색, 교육종합연 구 10(1), 67 88.

박성미(2008). 기업에서 요구하는 직업기초능력에 대한 델파이 분석, 수산해양교육연구 20(1), 12 22.

박정순(2004). 디자인 교육의 패러다임 변화와 디 자인 교육의 특성화, 진로논단 9, 459 482.

민경우·이순종·채승진(2005). 우리나라 디자인 교육에서 다학제 접근의 방향, 한국디자인학회 학술발표대회 논문집 5, 226 227.

오헌석 · 김희정 - 배형준 · 서동인 · 김한솔(2012). 융합학문 어떻게 탄생하는가, 교육문제연구 43 , $51 \sim 82$.

이대현(2008). 직관에 관한 연구 역사와 수학교육 적 의미 고찰, 한국학교수학회 11(3), 363 376.

이의수 · 조성구 · 이용한 · 이명천 · 염세경(2006). 복합학제 설계 교과목 운영사례와 학습효과 분 석, 공학교육연구 9(4), 10 18.

이순종 · 김종원 · 주우진 · 채승진 · 윤수현(2007). 다학제적 접근을 통한 대학 디자인 교육혁신 프로그램 연구, 디자인학연구 71, 299 314.

이정열 - 이주명(2010). 디자인사고의 의미비교, 한국디자인학회 학술발표대회 논문집 10, 62 63.

이지선 - 윤주현(2009). 테크놀로지 분야의 창의적 발상을 위한 디자인 사고 적용, 디지털디자인 학연구 9(4), 344 352.

윤호창(2004). 수학의 주관과 객관에 관하여. 한 국정신과학회 학술대회 논문집 $20,47 \sim 57$.

정연숙.김현경 역(2011). 디자인 통합, Sharon H. P. \& Keiichi, S.(2009), Design Intergrations: Research and Collaboration.

정영기(2012). 철학과 공학의 융합사례 연구: 착 한공학을 중심으로, 동서철학연구 $63,271 ~ 291$.
조성구 · 이의수 · 이명천 · 이용한 · 염세경(2008). 해외사례 분석을 통한 복합학제 설계교육의 활 성화 방안, 공학교육연구 11(1), 114 122.

최영수·강현석(2011). Bruner의 내러티브 이론에 비추어 본 교육과정 통합 탐색, 교육사상연구 25(3), 189 220.

Bhavnani, S. H. \& Aldridge, M. D.(2000). Team work across disciplinary Borders: A bridge between college and the work place, Journal of Engineering Education, 13 16.

Custer, R. L. \& Claborne, D. M.(1992). Critical skill clusters for vocational education, Journal of Vocational Ectucation Research 17(4), 34 55.

Cross, N. G.(1990). The nature and nature of the design ability, Design Studies 11(3), 127 140.

Dawson, M. T., \& Brucker, P. S. 2001. The Utility of the Delphi Method in MFT Research, The American Journal of Family Therapy 29, 125 140.

Hassen, F., Keeney, S. \& McKenna, H. 2000. Research Guidelines for the Delphi survey technique, Journal of Advanced Nursing 32(4), 1008 1015.

Jay, D.(1984). Unpublished Theory of Design Lecture Note, Institute of Design, IIT.

Leong, B. D. \& Clark, H.(2003). Culture-Based knowledge: Towards New Design Thinking and Practice-A Dialogue, Design Issues 19(3), $48 \sim 58$.

Teal, R.(2010). Developing a (Non linear) Practice of Design Thinking, International Journal of ART and Design Education 29(3), 294 302.

Thomson, B. S.(1998). Creative Engineering Design, Fourth Edition, Okemos Press.

- 논문접수일 : 2013년 01월 06일

- 심사완료일 : 1차 - 2013년 01월 20일

- 게재확정일 : 2013년 01월 23일 